\title{
Voltage Harmonic Analysis of Typical PWM Strategies in a Dual Inverter with Floating Capacitor in the Partial-Load Condition
}

\author{
Akihito Mizukoshi* Student Member, Hitoshi Haga*a) Senior Member
}

(Manuscript received Jan. 00, 20XX, revised May 00, 20XX)

\begin{abstract}
This study aims to reduce the voltage harmonics, caused by pulse width modulation (PWM) in a dual inverter with a floating capacitor topology in the partial-load condition. This work provides an analysis strategy for the output voltage harmonics, which depend on the fundamental voltage, power factor angle, and PWM strategies. Herein, sinusoidal PWM (SPWM), third harmonic injection PWM (THIPWM), and discontinuous PWM (DPWM) are used as the conventional carrier-based modulation techniques, and space vector PWM (SVPWM) and near-state PWM (NSPWM) with reduced number of commutations are used as the proposed modulation methods. The validity of the theoretical analysis is then confirmed by experiments using an open-end winding induction motor. The voltage total harmonic distortion (THD) is reduced by maximizing the modulation indices of both inverters in each modulation method; the experimental results show that voltage THD reductions of $10.9 \%$ with NSPWM and $17.3 \%$ with SVPWM can be obtained compared with that of SPWM. The total efficiency, including the inverter and motor efficiencies, is improved by up to $2.6 \%$ in the low load region (at a torque of $0.5 \mathrm{Nm}$ and fundamental frequency of $10 \mathrm{~Hz}$ ) when using the SVPWM.
\end{abstract}

Keywords: Open-end winding, induction motor, dual inverter, floating capacitor, PWM strategy.

\section{Introduction}

Pulse width modulated (PWM) inverters are used to achieve variable speed drives such as, electric vehicles, air conditioners, flywheel energy storages, etc. The motor drive systems require a high-efficiency operation not only at a rated-load condition. In particular, in air conditioner applications, efficiency improvement in the light to middle load range, in which the load is $75 \%$ or less, is required ${ }^{(1)}$. The operating time of a compressor such as a room air-conditioner is longer than the rated condition for a partial-load. In order to improve the energy saving of the air-conditioner, it is effective to improve the efficiency of partial-load. The inverter output voltage includes a carrier frequency component, which is increased when the motor driven at partial-load condition, and the high frequency causes motor loss. Furthermore, $29 \%$ of the motors, which were installed in 1992, are operating in the facilities with less than $50 \%$ load, which is reported in (2). Therefore, efficiency improvement of the motor drive system in the partial-load is effective for an energy-saving.

A circuit topology using a dual inverter has some advantages compared with a single inverter topology such as, expanded speed range ${ }^{(3),(4)}$, multilevel operation ${ }^{(5)}$, (6), and fault tolerant functions (7), (8). In recent years, input current harmonic suppression methods have also been investigated in the dual inverter with floating capacitor topology, in order to satisfy harmonic regulation or suppress the stress of capacitors; it can be achieved by using active and reactive power compensation ${ }^{(9)}\left({ }^{10)}\right.$. Conventionally, methods of reducing voltage harmonics by making the floating capacitor voltage the same as or half of the primary side DC voltage has been studied $^{(4),(6)}$. On the other hand, a method of controlling the floating capacitor voltage variable, in order to improving the performance,

a) Correspondence to: Hitoshi Haga. E-mail: hagah@vos.nagaokaut.ac.jp

* Nagaoka University of Technology.

1603-1, Kamitomioka-machi, Nagaoka, Niigata, Japan 940-2188 depending on the load condition has been studied ${ }^{(11)}$. However, sufficient studies have not been conducted on the reduction of voltage harmonics, which supplied to motor winding, in the partialload region.

In the dual inverter system, since the output voltage difference between both inverters is applied to the windings; thus, there is a degree of freedom in the modulation indices and phase angle difference (PAD) under the same fundamental voltage and power factor angle (PFA) conditions ${ }^{(3)}$. Therefore, it is necessary to investigate the driving method of the dual inverter according to various purposes and load conditions. Various modulation methods and those output voltage harmonics in a single inverter have been studied ${ }^{(12),(13)}$. In these studies, the harmonic voltage is evaluated by calculating the difference between the output voltage including harmonics and the voltage reference; and various PWM methods are compared for the harmonics in a switching period and in a fundamental period. In a dual inverter system with two isolated power supplies, a modulation method that does not use zero vectors to reduce output voltage harmonics and zero-sequence voltage has been proposed and theoretically analyzed ${ }^{(14)}$. However, modulation strategy, in a system where one side of DC link is floating capacitor in order to make the voltage in variable, has not been investigated.

The authors have been working on a waveform improvement especially focuses on the partial-load condition of the OEWIM ${ }^{(15),}$ (16). Through previous work, it has been confirmed that the voltage harmonics due to PWM switching can be reduced by keeping modulation indices of both inverters at maximum value and regulating the floating capacitor voltage at minimum ${ }^{(17)}$. However, in the dual inverter with floating capacitor topology, there are few studies to PWM each of the two inverters. In particular, modulation methods for reducing the harmonics of the output voltage depending on the load conditions are not investigated. In this paper, a theoretical analysis of output voltage harmonics when using various PWM methods are introduced. Here, sinusoidal PWM (SPWM), third harmonic injection PWM (THIPWM), and 


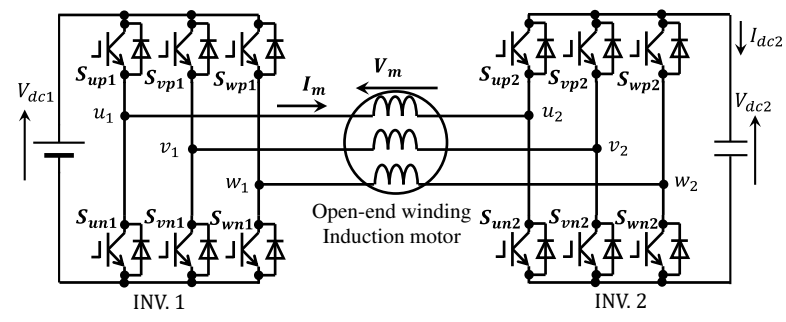

Fig. 1. Dual-inverter circuit with a floating capacitor.

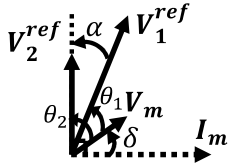

(a)

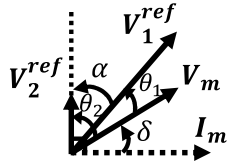

(b)
Fig. 2. Relationship of fundamental vectors in the dual-inverter with proposed method ${ }^{(17)}$, when the output voltage $\left|\boldsymbol{V}_{\boldsymbol{m}}\right|$ is (a) low and (b) high.

discontinuous PWM (DPWM) are used as conventional carrierbased modulation, and space vector modulation (SVPWM) and near-state PWM (NSPWM) ${ }^{(18)}$ with a reduced number of commutations are used as proposed modulation. Originality of this paper is to analyze the output voltage harmonics that change not only with the fundamental voltage but also with the PFA when typical PWM methods are applied to the dual inverter. Through analysis, this paper clarifies the modulation method that minimizes the harmonic components depending on the operating conditions of OEWIM. Since voltage harmonics are one of the cause of motor losses ${ }^{(19)}$, the efficiency of the motor drive system can be improved by selecting a modulation method that can reduce the harmonics in the partial-load condition. Furthermore, there is almost no change in the low-order components due to these modulation methods shown in this paper. Therefore, this paper does not mention loworder harmonics.

This paper is organized as follows: firstly, the configuration of the dual inverter fed open-end winding induction motor (OEWIM) drive system and basis of the floating capacitor topology are introduced; secondly, principle of voltage harmonics, which are related to fundamental voltage and power factor angle (PFA) is theoretically analyzed; finally, the experimental validation, which demonstrates the reduction of voltage harmonics and effectiveness of the voltage THD reduction by using proposed modulation is carried out.

\section{Dual inverter with Floating Capacitor Topology}

2.1 Circuit Configuration A circuit configuration of the dual inverter with the floating capacitor for the OEWIM is shown in Fig. 1. The system consists of an OEWIM and two 2-level voltage source inverters (VSIs), which are connected to the opposite terminals of stator windings, and the dual inverter is powered by a single DC voltage source. The primary inverter (INV. 1) has a DC power supply, and the secondary inverter (INV. 2) has a capacitor. The output voltage difference between INV. 1 and INV. 2 is supplied to the stator windings, the winding voltage vector $\boldsymbol{V}_{\boldsymbol{m}}$ is expressed as follows:

$$
\begin{aligned}
& V_{\boldsymbol{m}}=V_{1}-V_{2} \\
& \left|V_{1}\right|=\frac{M_{1}}{2} V_{d c 1},\left(0 \leq M_{1} \leq \frac{2}{\sqrt{3}}\right)
\end{aligned}
$$

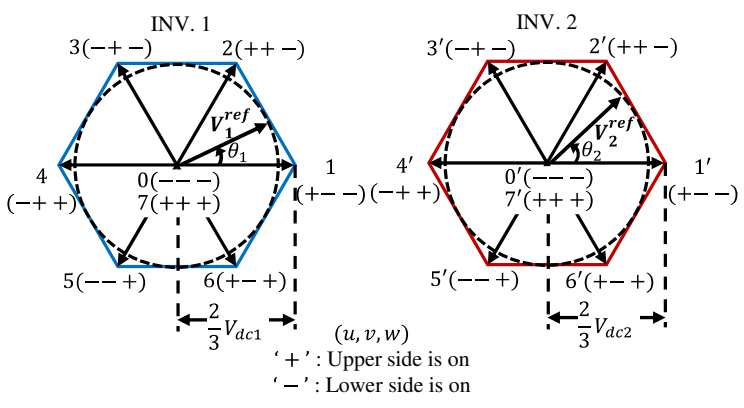

(a)

(b)

Fig. 3. Voltage space vector diagrams by (a) INV. 1 and (b) INV. 2.

$$
\left|\boldsymbol{V}_{2}\right|=\frac{M_{2}}{2} V_{d c 2},\left(0 \leq M_{2} \leq \frac{2}{\sqrt{3}}\right)
$$

Here, $\boldsymbol{V}_{\mathbf{1}}$ and $\boldsymbol{V}_{\mathbf{2}}$ indicate the output voltage vectors of INV. 1 and INV. 2 whose amplitudes of fundamental voltage are represented as (2) and (3), respectively. By injecting zero-sequence component, a maximum value of modulation indices $M_{1}$ and $M_{2}$ is defined as $2 / \sqrt{3} \cong 1.154$ within linear modulation ${ }^{(20)}$. Fig. 2 shows the vector diagrams of the dual inverter, which indicates the relationship between $\boldsymbol{V}_{\boldsymbol{m}}, \boldsymbol{V}_{\mathbf{1}}$, and $\boldsymbol{V}_{\mathbf{2}}$. Here, $\alpha$ denotes the phase angle difference (PAD) between the inverters, and $\delta$ denotes the motor power factor angle (PFA). Because INV. 2 has no power supply, $\boldsymbol{V}_{\mathbf{2}}$ leads or lags from the motor phase current $\boldsymbol{I}_{\boldsymbol{m}}$ by 90 deg at the steady state. From the voltage vector relationship, the DC voltage ratio $G_{d c}\left(=V_{d c 2} / V_{d c 1}\right)$ is given by:

$$
\begin{aligned}
& \frac{\left|\boldsymbol{V}_{\mathbf{2}}\right|}{\left|\boldsymbol{V}_{\mathbf{1}}\right|}=\frac{\cos (\alpha+\delta)}{\cos \delta} \\
& G_{d c}=\frac{V_{d c 2}}{V_{d c 1}}=\frac{M_{1}}{M_{2}} \frac{\cos (\alpha+\delta)}{\cos \delta} \text {. }
\end{aligned}
$$

In (5), $M_{1}$ and $M_{2}$ are given parameter, while phase angle difference between INV. 1 and INV. $2 \alpha$ can be calculated from cosine formula as:

$$
\begin{array}{r}
\left|\boldsymbol{V}_{\boldsymbol{m}}\right|^{2}=\left|\boldsymbol{V}_{\mathbf{1}}\right|^{2}+\left|\boldsymbol{V}_{\mathbf{2}}\right|^{2}-2\left|\boldsymbol{V}_{\mathbf{1}}\right|\left|\boldsymbol{V}_{\mathbf{2}}\right| \cos \alpha \\
\quad=\operatorname{Sin}^{-1}\left(\frac{2\left|\boldsymbol{V}_{\boldsymbol{m}}\right|}{M_{1} V_{d c 1}} \cos \delta\right) \ldots \ldots \ldots \ldots \ldots \ldots \ldots \ldots \ldots \ldots \ldots \ldots \ldots \ldots
\end{array}
$$

By giving PAD $\alpha$ according to (7), $M_{1}$ and $M_{2}$ can be set to arbitrary values. Since DC voltage of INV. $2 V_{d c 2}$ follows (5), it changes depending on $\left|\boldsymbol{V}_{\boldsymbol{m}}\right|$ and $\delta$. Through previous work ${ }^{(17)}$, it has been confirmed that the output voltage harmonics can be reduced by assigning the modulation indices $\left(M_{1}=M_{2}\right)$ and maximum.

2.2 Voltage Vectors and Levels Space vectors on the individual 2-level VSIs are shown in Fig. 3. In this paper, the switching states of INV.1 and INV.2 are respectively numbered as $0,1,2, \ldots, 7$ and 0 ', 1 ', 2', ..., 7'. Here, a " +" means that the upper arm switch is in conduction, while a "-" means that the lower arm switch is in conduction. Hence, this dual inverter has $8 \times 8=64$ applicable switching states ${ }^{(21)}$. The voltage vectors 1 to 6 and 1 ' to 6 ' are active vectors having the magnitude of $2 / 3 V_{d c 1}$ and $2 / 3 V_{d c 2}$, while vectors $0,7,0^{\prime}$, and 7 ' are zero vectors having the magnitude of 0 .

The resulting vectors in the dual inverter $\boldsymbol{V}_{\boldsymbol{x} y}$ are given by the difference between each vectors of INV. 1 and INV. 2 as follows: 


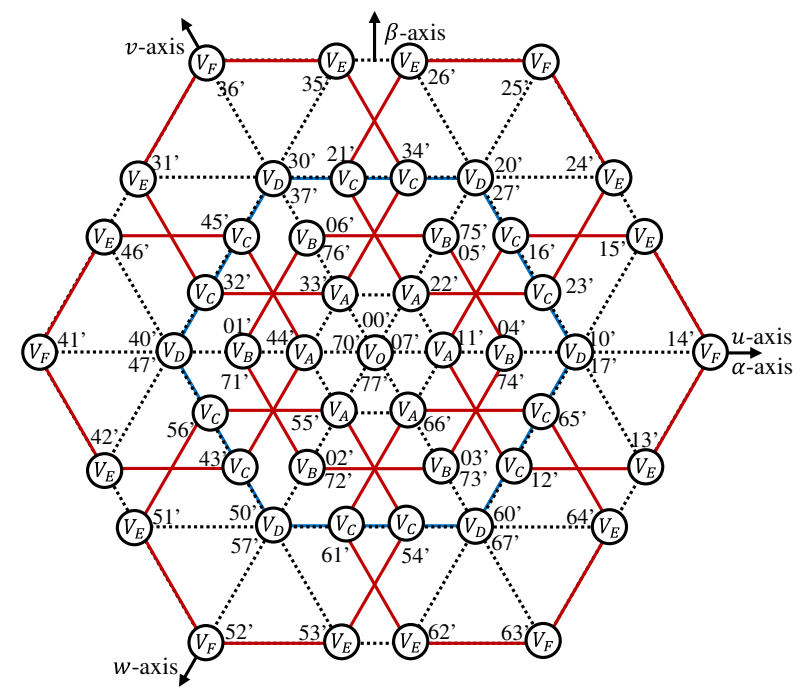

(a)

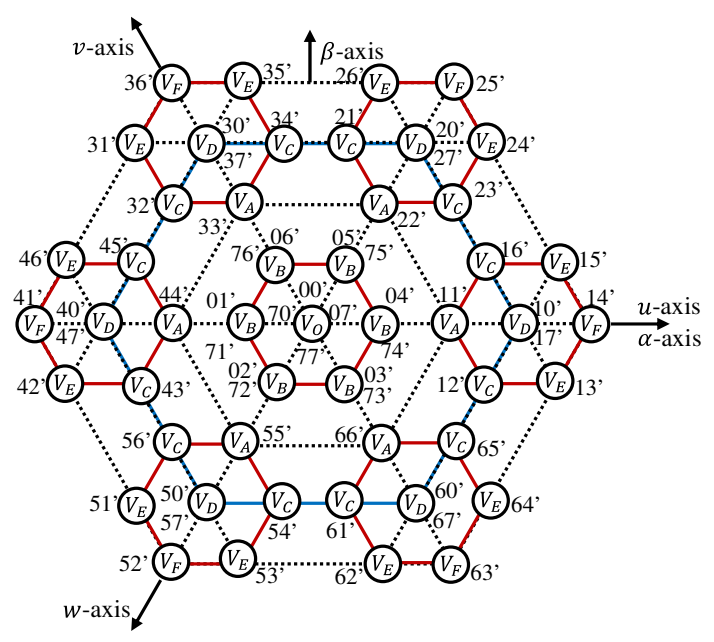

(b)

Fig. 4. Resulting space vectors by the dual-inverter when the voltage ratio $G_{d c}=V_{d c 2}: V_{d c 1}$ is (a) 2:3 and (b) 1:3.

$$
\boldsymbol{V}_{x y}=\left\{\begin{array}{l}
\frac{2}{3} V_{d c 1}\left(e^{j \frac{\pi}{3}(x-1)}-G_{d c} e^{j \frac{\pi}{3}(y-1)}\right), \\
\text { (if } x=1 \text { to } 6 \text { and } y=1 \text { to } 6), \\
\frac{2}{3} V_{d c 1} e^{j \frac{\pi}{3}(x-1)}, \\
\text { (if } x=1 \text { to } 6 \text { and } y=0,7), \\
\frac{2}{3} V_{d c 1} G_{d c} e^{j \frac{\pi}{3}(y-1)}, \\
\text { (if } x=0,7 \text { and } y=1 \text { to } 6)
\end{array}\right.
$$

where subscripts $x$ and $y$ denote the vector number. From (8), the resulting space vector diagram, as shown in Fig. 4, can be drawn as the hexagon by INV. 2 (in Fig. 3(b)) around vectors on the hexagon by INV. 1 (in Fig. 3(a)). The magnitudes of the resulting vector changes depending on the voltage ratio $G_{d c}$. For instance, the resulting vector diagrams for $G_{d c}=2: 3$ and $G_{d c}=1: 3$ are shown in Fig. 4(a) and (b), respectively. In this paper, voltage vectors are categorized into seven types according to their magnitude as follows:

$$
\begin{aligned}
& V_{A}=\frac{2}{3} V_{d c 1}\left(1-G_{d c}\right) \\
& V_{B}=\frac{2}{3} V_{d c 1} G_{d c} \\
& V_{C}=\frac{2}{3} V_{d c 1} \sqrt{1-G_{d c}+G_{d c}^{2}} \\
& V_{D}=\frac{2}{3} V_{d c 1} \\
& V_{E}=\frac{2}{3} V_{d c 1} \sqrt{1+G_{d c}+G_{d c}^{2}} \\
& V_{F}=\frac{2}{3} V_{d c 1}\left(1+G_{d c}\right) \\
& V_{O}=0
\end{aligned}
$$

By using the proposed control method ${ }^{(17)}, G_{d c}$ depends on the load conditions (fundamental voltage $V_{\text {fun }}$ and PFA $\delta$ ), according to (5) and (7). The magnitudes of each vector $V_{A}$ to $V_{O}$ with different fundamental voltage $V_{\text {fun }}$ at PFA of 45 deg are shown in Fig. 5, where PAD $\alpha$ is calculated by (7) and modulation indices

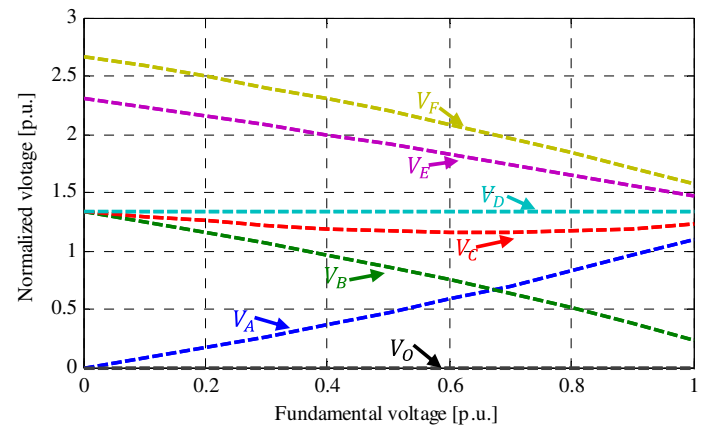

Fig. 5. Normalized magnitudes of voltage vectors $V_{A}$ to $V_{O}$ with different fundamental voltage $V_{\text {fun }}$ at PFA $\delta=45 \mathrm{deg}$.

are set at $M_{1}=M_{2}=1.15$. Here, the vertical and horizontal axes are normalized by the maximum fundamental voltage $\left(V_{d c 1} / 2\right)$, which value indicates the fundamental voltage at the maximum modulation index $\left(M_{1}=1\right)$ that can be linearly modulated with SPWM. From Fig. 5, in proportion to $V_{f u n}, V_{A}$ tends to increase and $V_{B}, V_{E}$, and $V_{F}$ tend to decrease; it indicates that, by increasing the output time of $V_{A}$ compared with other vectors, it is possible to reduce the harmonics with respect to the voltage reference vector.

In the following chapter, an analysis strategy of the harmonics generated by typical modulation methods based on the output times of each vector are described.

\section{Theoretical Analysis of the Voltage Harmonics}

3.1 Voltage References of Various PWM Strategies Many three-phase VSI modulation methods have been studied in terms of voltage utilization and input and output harmonics. In reference (12), the output voltage harmonics and input current harmonics in each common-mode voltage reduction method are evaluated in the single inverter topology. It has been reported that the larger the modulation index, the smaller the output voltage harmonics. In this paper, the output voltage harmonics when the modulation methods (THIPWM, DPWM, SVPWM, and NSPWM) that can maximize the voltage utilization is applied to the dual inverter system is evaluated.

The three-phase voltage references, in the case of SPWM strategy, are expressed by using modulation index $M$ and electrical angle $\theta$ 


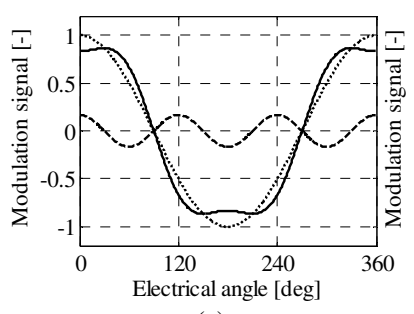

(a)

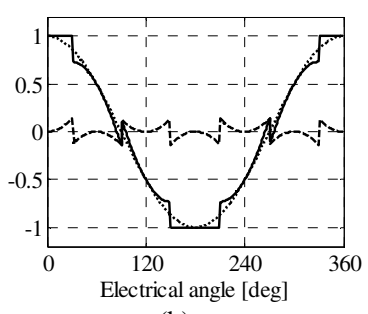

(b)
Fig. 6. Modulation signals of (a) THIPWM and (b) DPWM $(M=1)$.

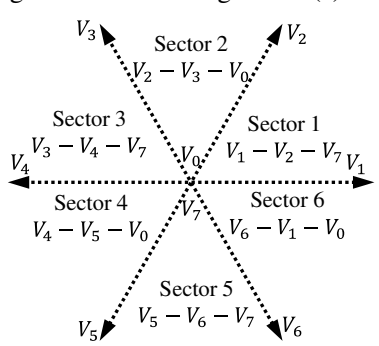

(a)

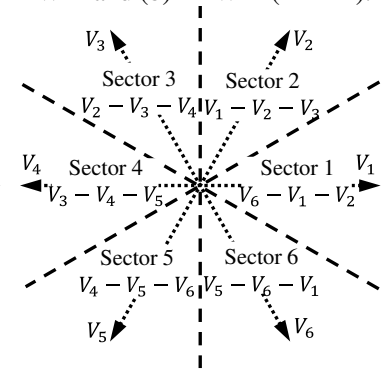

(b)
Fig. 7. Voltage sector definitions and output vector patterns of (a) SVPWM and (b) NSPWM.

as follows:

$$
\left\{\begin{array}{l}
d_{u-S P W M}=M \cos (\theta) \\
d_{v-S P W M}=M \cos \left(\theta-\frac{2}{3} \pi\right) \\
d_{w-S P W M}=M \cos \left(\theta+\frac{2}{3} \pi\right)
\end{array}\right.
$$

where $\theta$ is taken as the corresponding electrical angle when the rotor rotates. The methods of injecting zero-sequence component are well known as a method of expanding the modulation index keeping linearity, such as THIPWM and DPWM ${ }^{(13)}$. The threephase voltage references of THIPWM and DPWM are given by injecting the zero-sequence component $d_{z}$ into the sinusoidal references as:

$$
\begin{aligned}
& d_{x-T H I P W M}=d_{x-S P W M}-d_{z-T H I P W M},(x=u, v, w) \\
& d_{z-T H I P W M}=\frac{1}{6} M \cos (3 \theta) \ldots \ldots \ldots \ldots \ldots \ldots \ldots \ldots \ldots \ldots \ldots \ldots \ldots \ldots \\
& d_{x-D P W M}=d_{x-S P W M}+d_{z-D P W M},(x=u, v, w) \ldots \ldots \ldots \\
& \left\{\begin{array}{l}
d_{z-D P W M}=1-\left|d_{\text {max }}\right|, \text { if }\left|d_{\max }\right|>\left|d_{\min }\right| \ldots \ldots \ldots \ldots \\
d_{z-D P W M}=-1+\left|d_{\min }\right|, \text { if }\left|d_{\max }\right|<\left|d_{\min }\right|
\end{array}\right. \\
& \left\{\begin{array}{l}
d_{\max }=\max \left(d_{u-S P W M}, d_{v-S P W M}, d_{w-S P W M}\right) \ldots \ldots \ldots \ldots \\
d_{\min }=\min \left(d_{u-S P W M}, d_{v-S P W M}, d_{w-S P W M}\right)
\end{array}\right.
\end{aligned}
$$

The U-phase voltage references $d_{u}$ and zero-sequence component $d_{z}$ of THIPWM and DPWM when the modulation index $M=1$ are shown in Fig. 6(a) and (b), respectively. The switching states are directly obtained by comparing these voltage references and the carrier waveform (triangle waveform is used in this paper).

On the other hand, for the various purposes (e.g. reducing common-mode voltage and input current harmonics), a method of achieving a voltage reference vector by three voltage vectors and their output times has been proposed ${ }^{(18)}$. In this paper, SVPWM and NSPWM are used in which each inverter can output the maximum voltage $(M=2 / \sqrt{3})$. Voltage sector definitions and output vector patterns of SVPWM and NSPWM are shown in Fig. 7. The normalized duty cycles of SVPWM, per switching period $T_{S}$ for vectors of $V_{i}, V_{i+1}, V_{0,7}$ at sector $i$, are defined as:

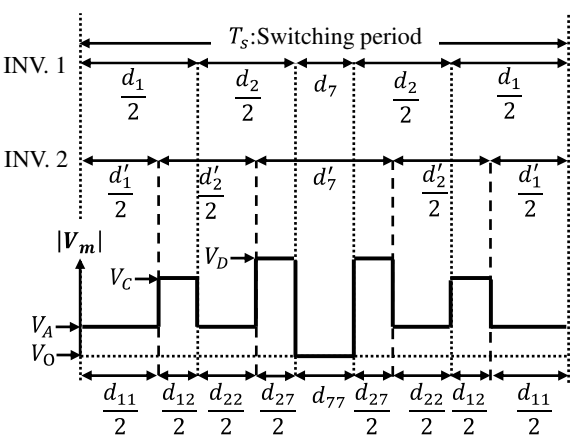

(a)

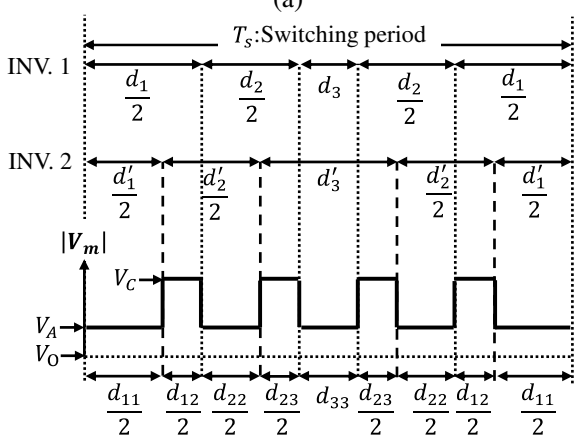

(b)

Fig. 8. Per-switching period view of each inverter states and output voltage by (a) SVPWM and (b) NSPWM.

$$
\begin{gathered}
\left\{\begin{array}{c}
d_{i-S V P W M}=\frac{\sqrt{3}}{2} M \cos \left(\theta^{\prime}+\frac{\pi}{6}\right) \\
d_{i+1-S V P W M}=\frac{\sqrt{3}}{2} M \sin \left(\theta^{\prime}\right) \\
d_{0,7-S V P W M}=1-\frac{\sqrt{3}}{2} M \cos \left(\theta^{\prime}-\frac{\pi}{6}\right) \\
\text { where } 0<\theta^{\prime}<\frac{\pi}{3}
\end{array}\right. \\
\theta^{\prime}=\theta-\frac{(i-1) \pi}{3},(i=1,2,3,4,5,6) \cdots \cdots \cdots
\end{gathered}
$$

Similarly, the normalized duty cycles of NSPWM, per switching period $T_{S}$ for vectors of $V_{i-1}, V_{i}, V_{i+1}$ at sector $i$, are defined as:

$$
\begin{aligned}
& \left\{\begin{array}{c}
d_{i-1-N S P W M}=1-\frac{\sqrt{3}}{2} M \cos \left(\theta^{\prime}-\frac{\pi}{6}\right) \\
d_{i-N S P W M}=\frac{3}{2} M \cos \left(\theta^{\prime}\right)-1 \\
d_{i+1-N S P W M}=1-\frac{\sqrt{3}}{2} M \cos \left(\theta^{\prime}+\frac{\pi}{6}\right)
\end{array}\right. \\
& \theta^{\prime}=\theta-\frac{(i-1) \pi}{3},(i=1,2,3,4,5,6) \cdots \cdots \cdots
\end{aligned}
$$

In this paper, each vector is output in the switching pattern shown in Fig. 8 in order to reduce the number of commutations in a switching period in the case of SVPWM and NSPWM.

3.2 Output Times of each Vector in Dual Inverter When using carrier-based PWM, the output time $d_{x y}$ of each vector, which normalized by a switching period $T_{s}$, is determined by the relation between voltage references of INV. 1, and INV. 2 . Here, voltage references are calculated by substituting $M_{1}$ or $M_{2}$ for $M$, and $\theta_{1}$ or $\theta_{2}$ for $\theta$ in equations (10) to (14), in which the electrical angle of INV. 1 and INV. $2\left(\theta_{1}\right.$ and $\left.\theta_{2}\right)$ are given by $\theta-$ $\delta-\alpha+\pi / 2$, and $\theta_{1}-\alpha$ respectively (see Fig. 2). Note that there are 64 switching states, $d_{x y}$ are described below as examples: 


$$
\begin{aligned}
& d_{11}=\min \left(d_{u 1}, d_{u 2}\right)-\max \left(d_{v 1}, d_{w 1}, d_{v 2}, d_{w 2}\right) \\
& d_{12}=\min \left(d_{u 1}, d_{u 2}, d_{v 2}\right)-\max \left(d_{v 1}, d_{w 1}, d_{w 2}\right)
\end{aligned}
$$

On the other hand, in the SVPWM and NSPWM methods in which output times of each vector $\left(d_{x}\right.$ and $\left.d^{\prime}{ }_{y}\right)$ is calculated from the voltage reference vector, as shown in Fig. 8. Here, $x$ denotes the vector number of INV. 1 and $y$ denotes the vector number of INV. 2, while the characters with' indicate variables of INV. 2. The output times $d_{x y}$ are calculated as follows:

$$
\begin{aligned}
& d_{11}=\min \left(d_{1}, d_{1}^{\prime}\right) \\
& d_{12}=\max \left(d_{1}, d_{1}^{\prime}\right)-\min \left(d_{1}, d_{1}^{\prime}\right)
\end{aligned}
$$

As shown in Fig. 8, the output voltage vector is determined by the combination of the voltage vectors of the two inverters in the dual inverter topology. The output times $d_{K}$ of each categorized vectors $V_{K}$ are obtained by calculating the sum of $d_{x y}$ that match the category (see Fig. 4) as follows:

$$
d_{K}(\theta)=\sum_{x} \sum_{y} d_{x y}(\theta)
$$

where subscript $K=A, B, C, D, E, F, O$. The characteristics of $d_{K}$, which change depending on the electrical angle $\theta$ according to (16), are shown in Fig. 9. Here, the fundamental voltage $V_{\text {fun }}$ and the PFA $\delta$ are set to 0.67 and $45 \mathrm{deg}$, respectively. From the results, the following features are confirmed: In the four modulation methods, $d_{A}$ is larger than the others, $d_{C}$ is the second largest, and $d_{F}$ is always zero. $d_{E}$ is zero in SVPWM and NSPWM, which leads to a reduction in the maximum voltage level compared to THIPWM and DPWM. In NSPWM, the change in voltage level is reduced because the values other than $d_{A}$ and $d_{C}$ are zero.

$d_{K}$ changes not only with the electric angle $\theta$ but also with the fundamental voltage $V_{\text {fun }}$ and the PFA $\delta$. Fig. 10 shows the average value of the output time $D_{K}$ in a fundamental period $T$, according to (17).

$$
D_{K}\left(V_{\text {fun }}, \delta\right)=\frac{1}{2 \pi} \int_{0}^{2 \pi} d_{K}(\theta) d \theta
$$

Here, the horizontal axis indicates the fundamental component of the output voltage, and the vertical axis is normalized by a fundamental period. From this result, it can be seen that $D_{A}$ and $D_{C}$ are dominant because $D_{B}, D_{D}, D_{E}$, and $D_{O}$ are smaller than $D_{A}$ and $D_{C}$. In Fig. 10(a), $D_{A}$ decreases as $V_{\text {fun }}$ increases, and $D_{A}$ is the largest in NSPWM at low $V_{f u n}$. On the other hand, at high $V_{\text {fun }}, D_{A}$ is large in DPWM and THIPWM. In Fig. 10(c), $D_{C}$ increases as the voltage increases, and $D_{C}$ is relatively larger in the case of NSPWM and SVPWM.

3.3 Harmonic Voltage in Per-Switching Period In the above section, the output time of each vector in various modulation methods is described. In this section, the voltage applied to the load

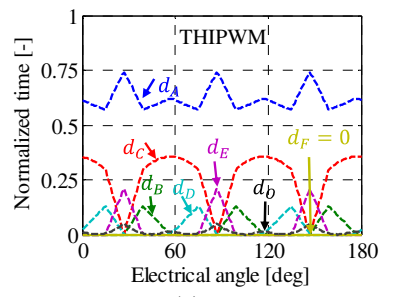

(a)

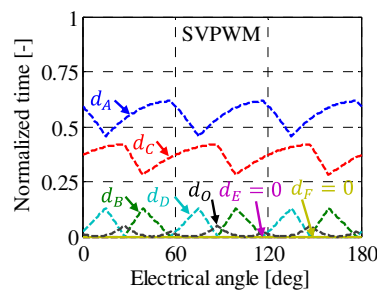

(c)

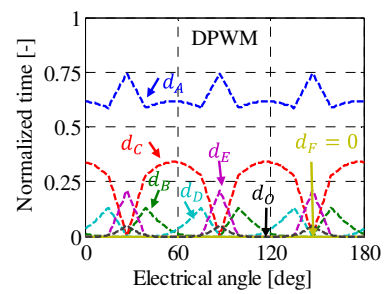

(b)

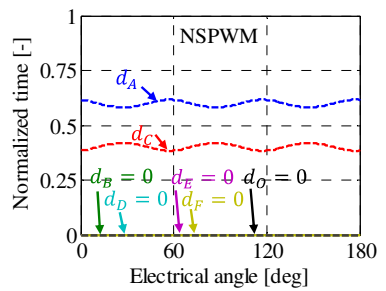

(d)
Fig. 9. Angle dependencies of the normalized output times $\left(V_{\text {fun }}=\right.$ 0.67 p. u. , $\delta=45 \mathrm{deg}$ )

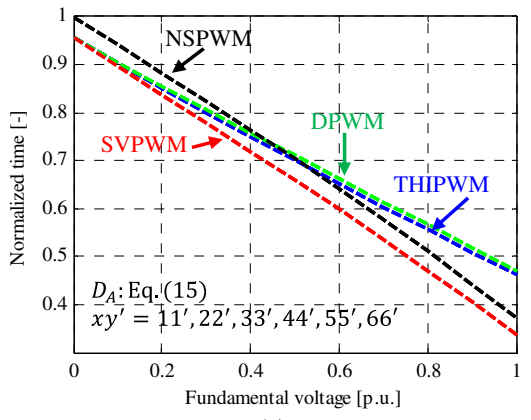

(a)

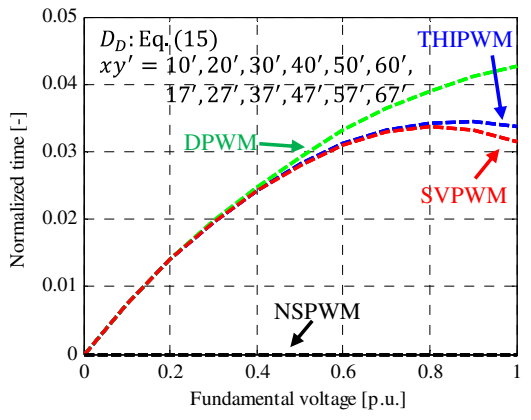

(d)

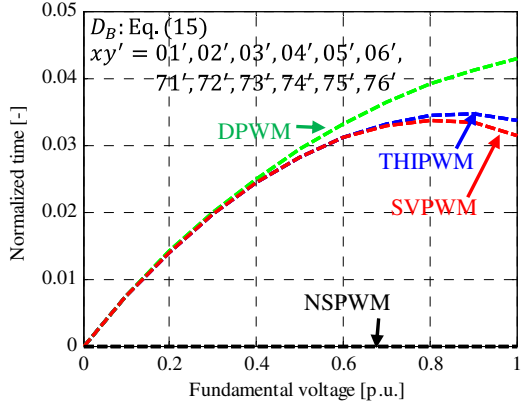

(b)

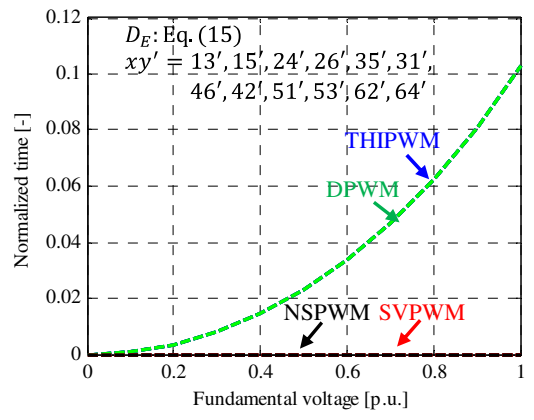

(e)

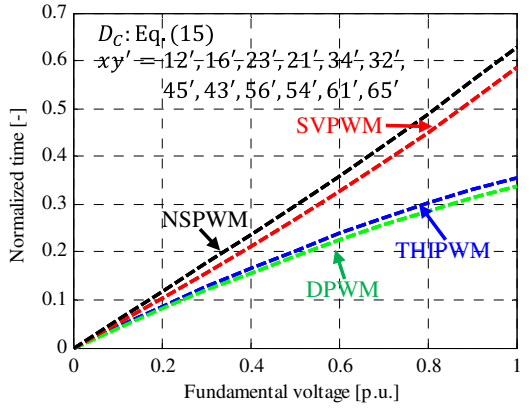

(c)

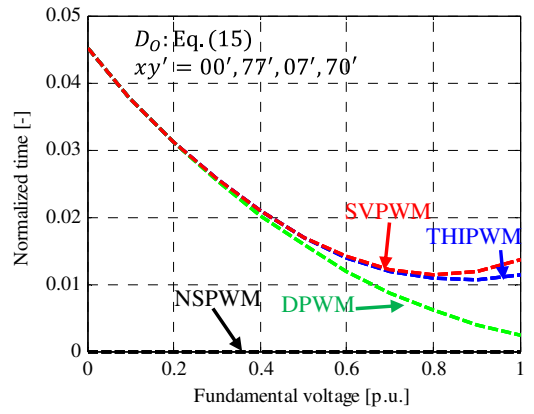

(f)

Fig. 10. Normalized output times of voltage vectors (a) $V_{A}$, (b) $V_{B}$, (c) $V_{C}$, (d) $V_{D}$, (e) $V_{E}$, and (f) $V_{O}$ when different fundamental voltage $V_{\text {fun }}$ and PFA $\delta$ is $45 \mathrm{deg}$. 
is calculated from those output time, and the generated harmonics are evaluated using root-mean-squared (RMS) value.

Output voltage RMS in per-switching period $V_{R M S}-S W$ is calculated by the sum of all combinations of the product of $V_{x y}^{2}$ and $d_{x y}(\theta)$ as follows:

$$
V_{R M S-S W}(\theta)=\sqrt{\sum_{x=0}^{7} \sum_{y=0}^{7} V_{x y}^{2} d_{x y}(\theta)}
$$

Here, $V_{R M S-S W}$ changes depending on the electrical angle $\theta$. When the difference between $V_{R M S-S W}$ and the voltage reference $V_{m-r e f}$ is large, it means that more harmonics are superimposed. In this paper, the harmonic voltage $V_{h n}$ are expressed as follows:

$$
\begin{aligned}
& V_{h n}(\theta)=\frac{\sqrt{V_{R M S-S W}^{2}(\theta)-V_{m-r e f}^{2}(\theta)}}{V_{\text {fun }}} \\
& \boldsymbol{V}_{\boldsymbol{m} \text {-ref }}=\left[\begin{array}{l}
v_{\text {um-ref }} \\
v_{\text {vm-ref }} \\
v_{\text {wm-ref }}
\end{array}\right]=V_{\text {fun }}\left[\begin{array}{c}
\cos (\theta) \\
\cos \left(\theta-\frac{2}{3} \pi\right) \\
\cos \left(\theta+\frac{2}{3} \pi\right)
\end{array}\right]
\end{aligned}
$$

where, the output voltage reference $V_{m-r e f}$ is defined in (20) as a three-phase voltage having a fundamental amplitude of $V_{\text {fun }}$. The harmonic voltage $V_{h n}$ is normalized by $V_{f u n}$, and as decreasing $V_{h n}$, the smaller the harmonics contained in the voltage waveform.

Fig. 11 shows the harmonic voltage characteristics (according to (19)) when the four modulation methods (THIPWM, DPWM, SVPWM, NSPWM) are used. As described in Section 2.2, the magnitude of each voltage vector changes depending on the fundamental voltage $V_{\text {fun }}$ and PFA $\delta$, thus the characteristics are calculated by changing $V_{\text {fun }}$. The vertical axis indicates the harmonic voltage $V_{h n}$, and the horizontal axis indicates the electric angle $\theta$. From this result, it can be seen that THIPWM and DPWM have almost the same characteristics even if $V_{\text {fun }}$ is changed. This is because the output time characteristics shown in Figs. 9 and 10 are almost the same. When $V_{\text {fun }}$ is 0.33 p.u., the peak of $V_{h n}$ is the largest in SVPWM and the smallest in NSPWM (see Fig. 11(a)). On the other hand, when $V_{\text {fun }}$ is 1.0 p.u., the average value is the smallest in SVPWM and the largest in NSPWM (see Fig. 11(c)).

3.4 Characteristics of Voltage THD In the previous section, the calculation method of the harmonic voltage in perswitching period is described. In this section, the voltage harmonics that change depending on the fundamental voltage $V_{f u n}$ and the

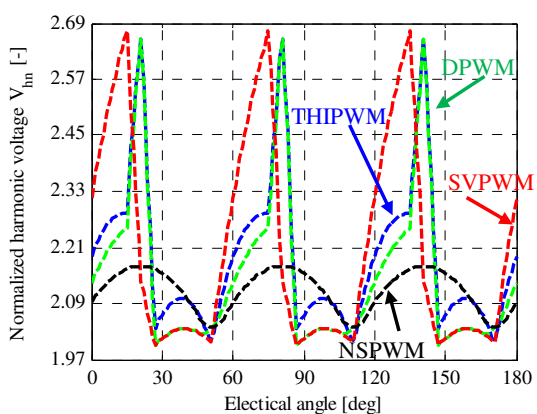

(a)

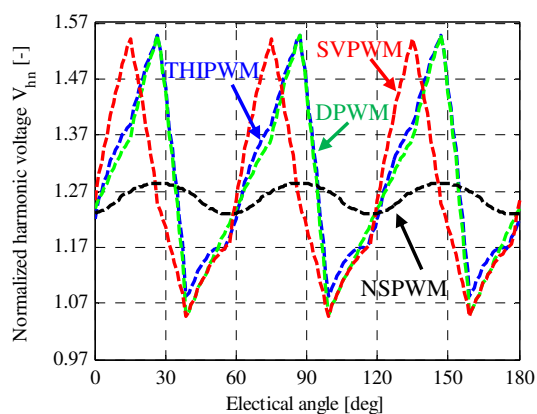

(b)

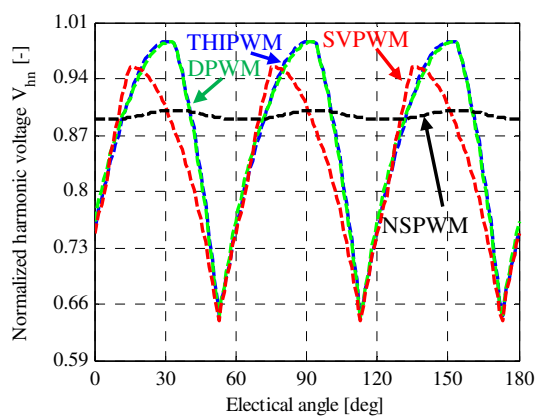

(c)

Fig. 11. Normalized harmonic voltage - angle characteristics at PFA of 45 deg with (a) $V_{\text {fun }}=0.33$ p.u., (b) $V_{\text {fun }}=0.67$ p.u., and (c) $V_{\text {fun }}=1.0$ p.u.

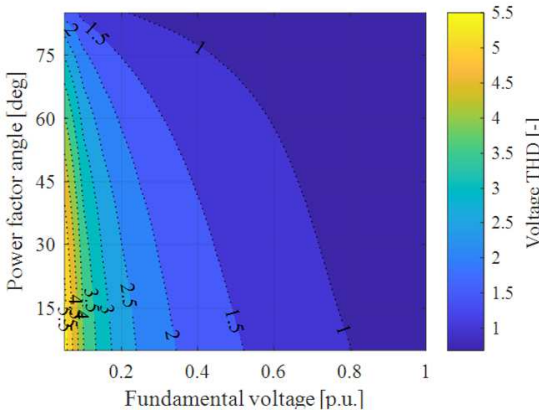

(a) SPWM

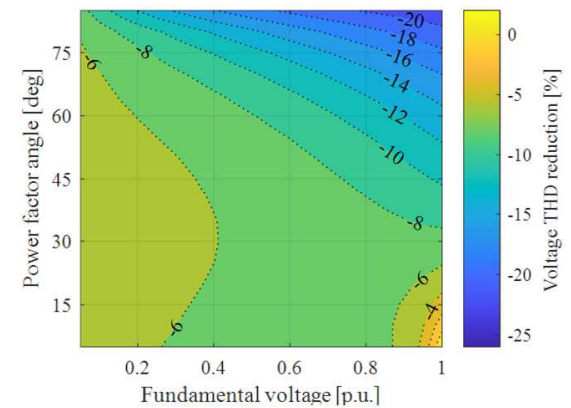

(b) THIPWM

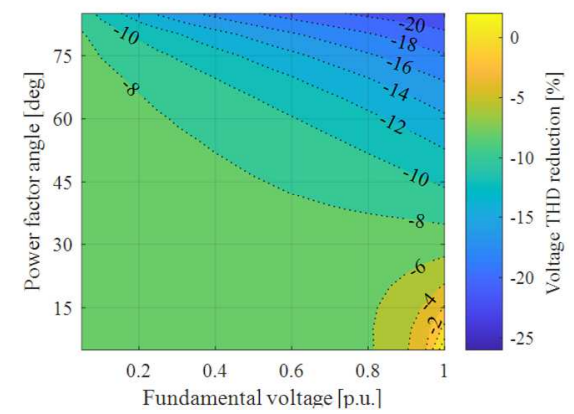

(c) DPWM

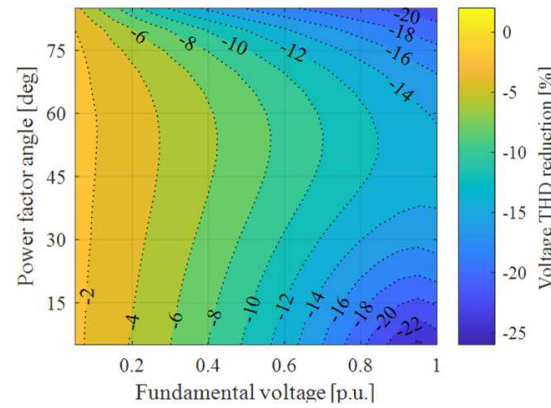

(d) SVPWM

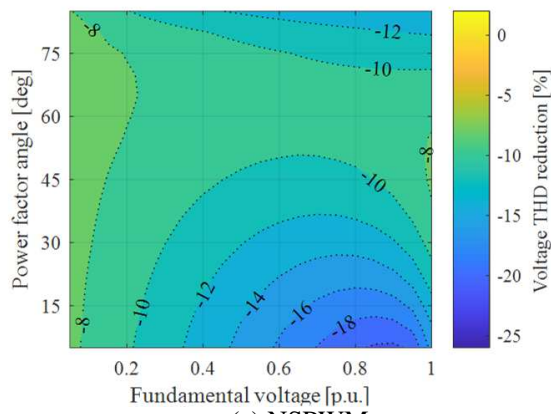

(e) NSPWM

Fig. 12. Voltage THD characteristics for different fundamental voltage and PFA with (a) SPWM, (b) THIPWM, (c) DPWM, (d) SVPWM, and (e) NSPWM. Note that the color bars in (b)-(e) show the reduction rate (in \%) based on the calculation results in (a). 

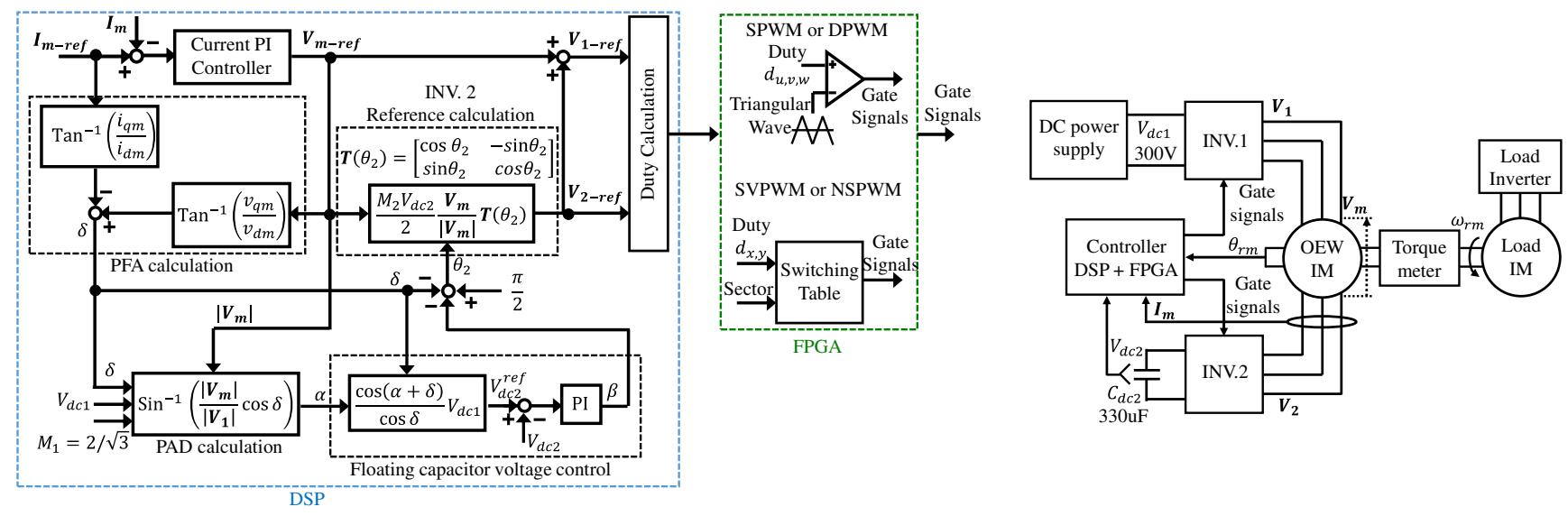

Fig. 13. Control block diagram.

Fig. 14. Experimental setup.

PFA $\delta$ are evaluated using total-harmonic-distortion (THD).

The voltage RMS in a fundamental period $V_{R M S}$ is expressed by using $V_{R M S-S W}$ as follows:

$$
V_{R M S}\left(V_{f u n}, \delta\right)=\sqrt{\frac{1}{2 \pi} \int_{0}^{2 \pi} V_{R M S-S W}^{2}(\theta) d \theta}
$$

Since THD is given by calculating the difference between the RMS value including all harmonics and the fundamental component, thus THD is obtained by calculating the RMS of the harmonic voltage $V_{h n}$ (expressed in (19)) as follows:

$$
\operatorname{THD}\left(V_{\text {fun }}, \delta\right)=\sqrt{\frac{1}{2 \pi} \int_{0}^{2 \pi} V_{h n}^{2}(\theta) d \theta}
$$

In this paper, in order to evaluate the voltage THD reduction for each modulation method, comparisons are carried out with the THD calculation result when SPWM is used. Fig. 12 shows the numerical calculation results of the output voltage THD in a fundamental period, according to (22), when the fundamental voltage $V_{\text {fun }}$ and PFA $\delta$ are changed. Here, the color bars in Fig. 12(b)-(e) show the reduction rate (in \%) based on the calculation results in SPWM. By using SPWM, the voltage THD reduction compared with the single inverter operation has been confirmed, in the region where $\delta$ is large and $V_{\text {fun }}$ is small, which result is reported in ${ }^{(17)}$. The following features is confirmed from the THD calculation results: THD is reduced compared to SPWM in all areas. In THIPWM, DPWM, and SVPWM, THD is reduced by about $20 \%$ in the region of high voltage $\left(V_{\text {fun }}=1\right.$ p. u.) and high PFA ( $\delta=75 \mathrm{deg}$ ) (see Fig. 12 (b), (c) and (d)). In SVPWM and NSPWM, the THD is most reduced at high voltage $\left(V_{\text {fun }}=1\right.$ p.u. $)$ and low PFA ( $\delta=$ $75 \mathrm{deg}$ ), and the reduction rates are $-22 \%$ and $-18 \%$, respectively (see Fig. 12 (d) and (e)). In NSPWM, the reduction rate is large in the region where $V_{\text {fun }}$ and $\delta$ are low (see Fig. 12 (d) and (e)).

From the numerical calculation results in this chapter, it is confirmed that the load conditions that can reduce the output voltage harmonics differ depending on the modulation method. The validity of the above theoretical calculation is demonstrated by experiments.

\section{Experimental Setup and Conditions}

Experiments using a general-purpose induction motor (TFO-FK $0.75 \mathrm{KW} 4 \mathrm{P} 200 \mathrm{~V}$, made by HITACHI) as OEWIM are carried out in order to compare the voltage harmonics in each modulation methods. The dual inverter conditions and parameters of the
Table 1. Experimental condition.

\begin{tabular}{cc}
\hline \hline INV.1 DC voltage: $V_{d c 1}$ & $300 \mathrm{~V}$ \\
\hline INV.2 DC voltage: $V_{d c 2}$ & According to Eq. (5) \\
\hline INV.2 DC capacitance: $C_{d c 2}$ & $330 \mathrm{uF}$ \\
\hline Carrier Frequency: $F_{c 1}$ & $5 \mathrm{kHz}$ \\
\hline Dead-time: $T_{D T}$ & $500 \mathrm{~ns}$ \\
\hline \hline
\end{tabular}

Table 2. Parameters of the OEWIM.

\begin{tabular}{cc|cc}
\hline \hline Rated power & $750 \mathrm{~W}$ & Poles & 4 \\
\hline Rated voltage & $200 \mathrm{~V}$ & Rated frequency & $50 \mathrm{~Hz}$ \\
\hline Rated current & $3.5 \mathrm{~A}$ & Rated speed & $1410 \mathrm{rpm}$ \\
\hline $\begin{array}{c}\text { Leakage } \\
\text { inductance }\end{array}$ & $10.5 \mathrm{mH}$ & Rated torque & $5.0 \mathrm{Nm}$ \\
\cline { 3 - 4 } & & Stator resistance & $2.74 \Omega$ \\
\hline Mutual inductance & $0.195 \mathrm{H}$ & Rotor resistance & $2.08 \Omega$ \\
\hline \hline
\end{tabular}

OEWIM are shown in Tables 1 and 2. In this experiment, a DC power supply regulates the INV. 1 DC voltage at $300 \mathrm{~V}$. The selection of the capacitance of the floating capacitor in various dual inverter drive methods is reported in ${ }^{(4)}$. It is known that in the operation method in which the sinusoidal voltage is output from both inverters, the sixth-order fluctuation of the DC voltage occurs due to the harmonic current caused by dead-time and spatial harmonics. This experiment focuses on verifying the reduction of voltage harmonics caused by PWM; thus, the capacitance was set to $330 \mathrm{uF}$ to sufficiently reduce the fluctuation of $V_{d c 2}$.

In order to control the torque and speed of the OEWIM, which are related to the PFA and output voltage, the motor current control and floating capacitor voltage control are performed using the control block as shown in Fig. 13. Through previous study, the output voltage harmonics reduction has been verified by outputting the voltage of the difference between the two inverters with $M_{1}$ and $M_{2}$ as the maximum ${ }^{(17)}$. In this control method, the maximum voltage of INV. 2 is output ( $M_{2}$ is the maximum), and the INV. 1 voltage reference $\boldsymbol{V}_{\mathbf{1}-\boldsymbol{r e f}}$ is obtained by adding the INV. 2 voltage reference $\boldsymbol{V}_{2-\text { ref }}$ to the motor voltage $\boldsymbol{V}_{\boldsymbol{m} \text {-ref }}$, which is obtained by the current PI controller, according to (1). Here, by substituting 
$M_{1}=M_{2}$ into (5) and (7), and controlling floating capacitor voltage $V_{d c 2}$ at that value, thus $M_{1}=M_{2}$ and their maximization are achieved. In this paper, the modulation part, which converts the voltage references $V_{1-r e f}$ and $V_{2-r e f}$ into gate signals of each inverter is changed. In this experiment, SVPWM and NSPWM generate gate signals according to the switching table using FPGA, and SPWM, THIPWM, and DPWM generate gate signals by comparing the triangular carrier and the three-phase voltage reference (see Fig. 13).

Fig. 14 shows an experimental setup. The three-phase stator current $I_{m}$, the floating capacitor voltage $V_{d c 2}$ (DC voltage of INV2), and the mechanical angle $\theta_{r m}$ of the rotor are measured for control. Here, the slip-frequency-type field-oriented control is used. In order to change the torque in proportion to the q-axis current, the d-axis current is controlled to be constant at 2.0 A. The torque is set from approximately $0.5 \mathrm{Nm}$ to $3.5 \mathrm{Nm}(10 \%$ to $70 \%$ of the rated torque) to verify the improvement effect in the partialload condition.

\section{Experimental Results}

5.1 Experimental Waveforms and Harmonic Analysis of the Output Voltage In this experiment, the steady state performances, in the case of using five modulation methods, are demonstrated, when the motor is driven with a torque of $0.5 \mathrm{Nm}$ and a fundamental frequency $F_{\text {fun }}$ of $50 \mathrm{~Hz}$; Under this condition, PFA $\delta$ of 75 deg and a fundamental voltage $V_{f u n}$ of $97.0 \mathrm{~V}(0.9$ p.u.) are obtained.

Fig. 15 shows the experimental waveforms of the motor phase voltage $v_{u m}$, phase current $i_{u m}$, floating capacitor voltage $V_{d c 2}$, and each inverter voltage references $d_{u 1}$ and $d_{u 2}$. Here, the bottom waveform of SVPWM and NSPWM (shown in Fig. 15 (d) and (e)) indicates the equivalent output voltage of each inverter. Since the maximum value of each voltage reference are 1.0 in all modulation methods, it can be confirmed that the proposed control method has been realized (see the bottom of Fig. 15). The reason why the floating capacitor voltage $V_{d c 2}$ (third waveform from the top) is approximately $40 \mathrm{~V}$ in (a) SPWM and about $70 \mathrm{~V}$ in other cases is because the modulation index is set to 1.00 and 1.15 , respectively, and $V_{d c 2-r e f}$ is determined by (5). During the period when the voltage references are constant at 1.0 (which can be seen by (c) DPWM, (d) SVPWM, (e) NSPWM), the change in the phase voltage level is small, hence the switching ripple in the current waveform is reduced. In particular, the voltage waveform in NSPWM has less change in voltage level than other methods (which can be seen in Fig. 10 in Section 3.2).

The harmonic analysis results of the phase voltage waveform (top waveforms in Fig. 15) are shown in Fig. 16, in which the vertical axis is normalized by the fundamental voltage $V_{\text {fun }}=$ 97.0 V. Here, $V_{C x}$ represents the peak of the harmonic component at a $x$ times of the carrier frequency. $V_{C X}$ in each methods indicate that: $V_{C 1}$ is the largest in the case of (e) NSPWM, and it is small in the case of (b) THIPWM, (c) DPWM, and (d) SVPWM. On the other hand, $V_{C 2}, V_{C 3}$, and $V_{C 4}$ are the largest in the case of (a) SPWM and decrease in other methods. Furthermore, the sideband of the carrier frequency is shown on the right side of Fig. 16 , where $\pm x F_{\text {fun }}$ denotes a sideband component $x$ times of the fundamental frequency $\left(F_{\text {fun }}=50 \mathrm{~Hz}\right)$ centered on the carrier frequency $\left(F_{C 1}=5 \mathrm{kHz}\right)$. In (a) SPWM, (b) THIPWM, and (c) DPWM, $F_{C 1}$ and even-numbered components of $F_{\text {fun }}$ exist, and in THIPWM and DPWM, the zero-phase component is added to the

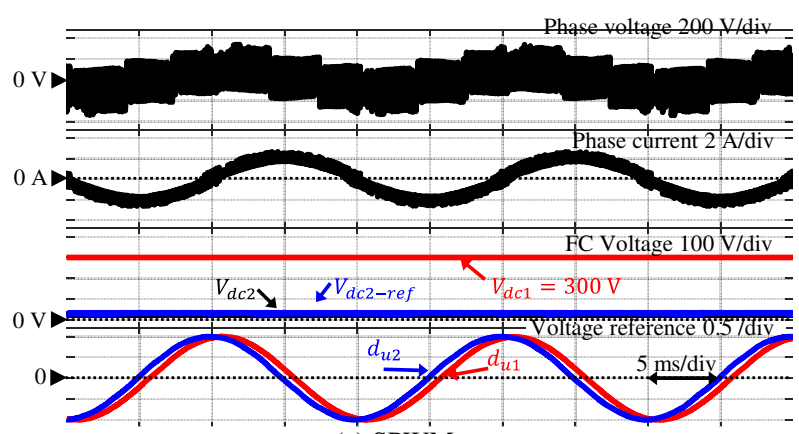

(a) SPWM

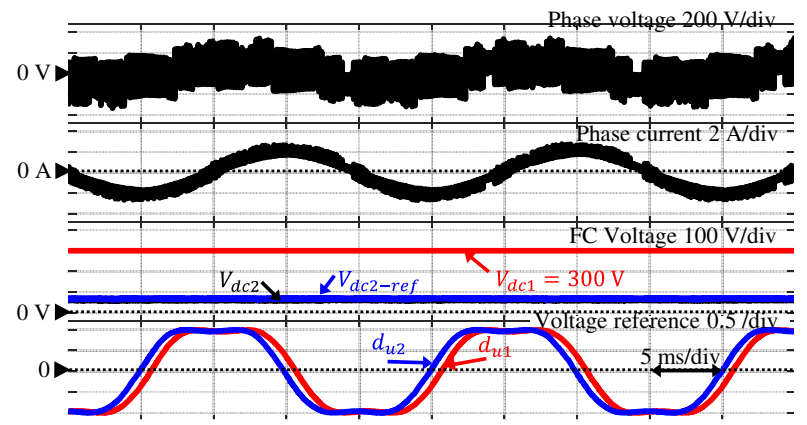

(b) THIPWM

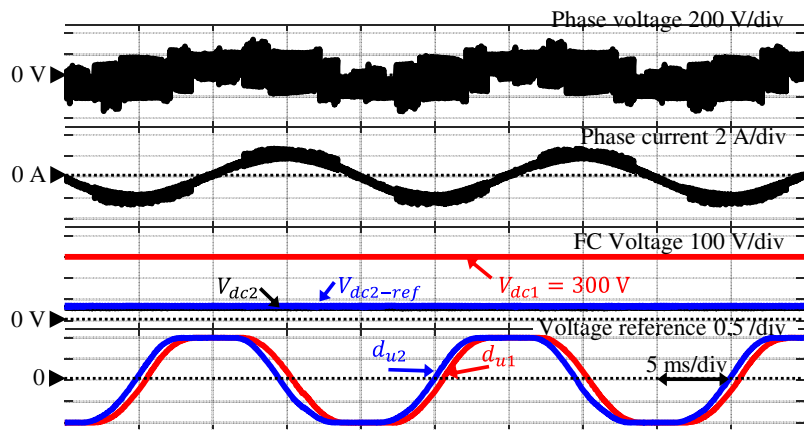

(c) DPWM

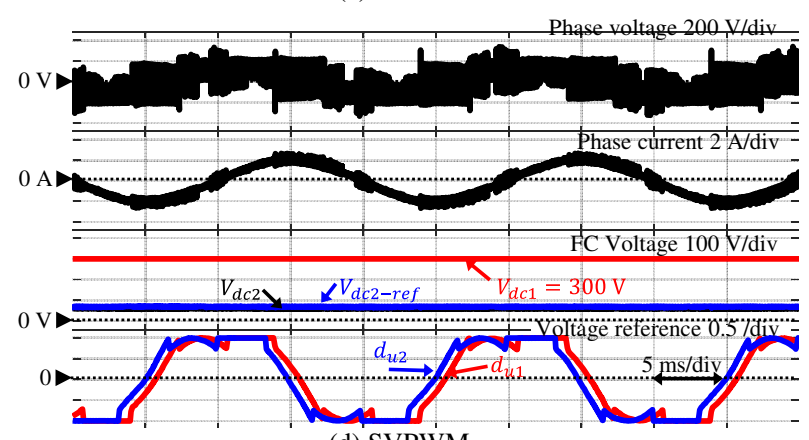

(d) SVPWM

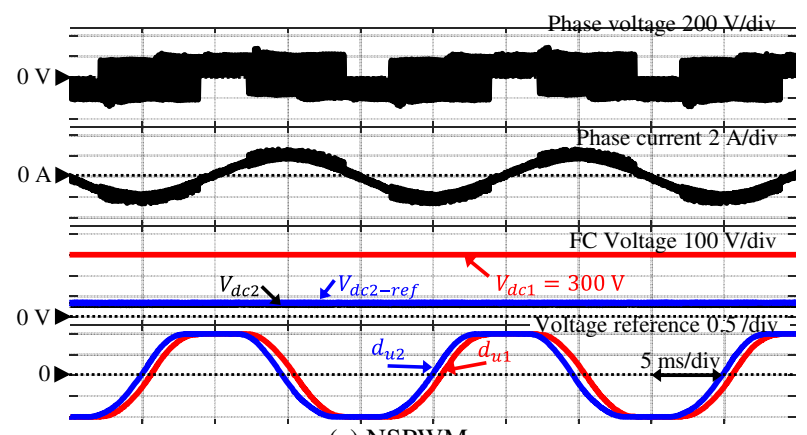

(e) NSPWM

Fig. 15. Experimental waveforms for each modulation methods at a torque of $0.5 \mathrm{Nm}$ and a fundamental frequency $F_{f u n}$ of $50 \mathrm{~Hz}$ (Phase voltage, phase current, floating capacitor (FC) voltage, and voltage references). 


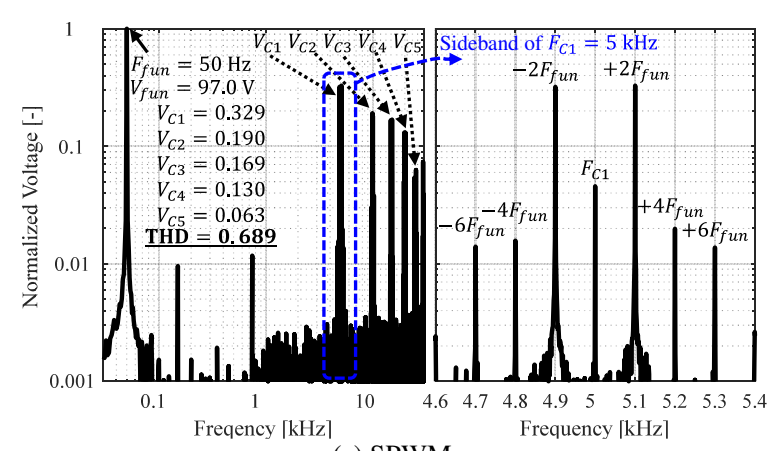

(a) SPWM

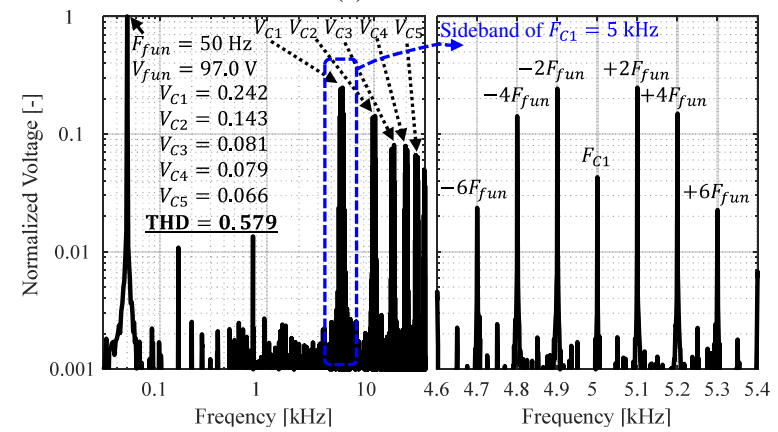

(b) THIPWM

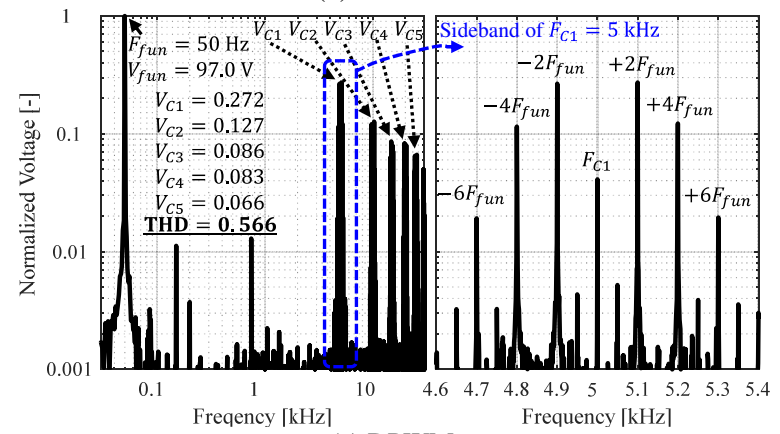

(c) DPWM

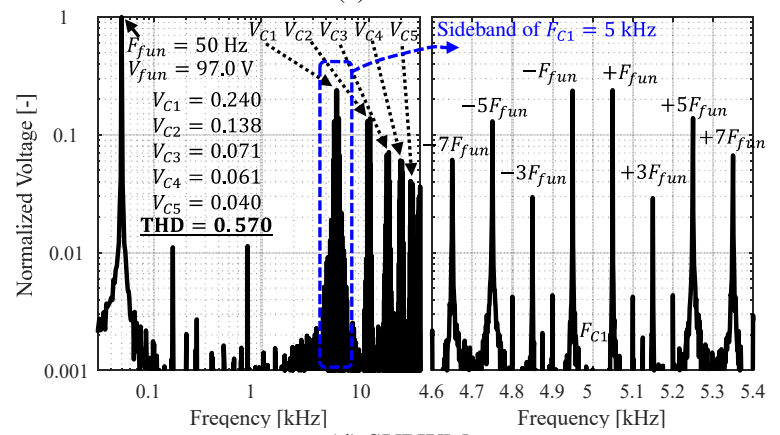

(d) SVPWM

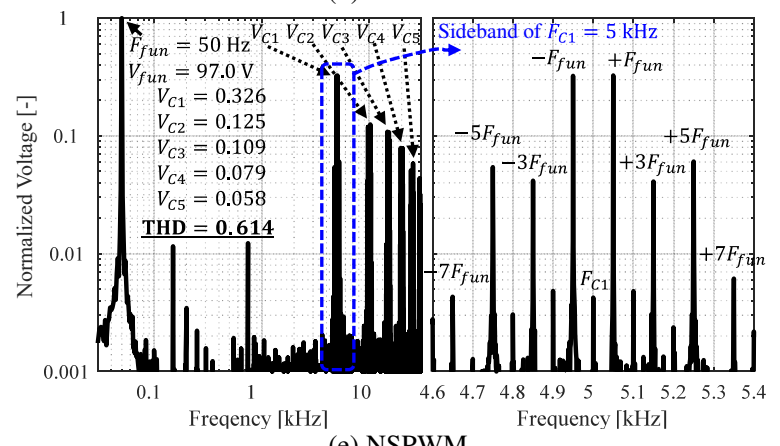

(e) NSPWM

Fig. 16. Results of the phase voltage harmonic analysis for each modulation methods at a torque of $0.5 \mathrm{Nm}$ and a fundamental frequency $F_{\text {fun }}$ of $50 \mathrm{~Hz}$ (Right side: Sideband of carrier frequency $F_{c 1}=5 \mathrm{kHz}$ ).

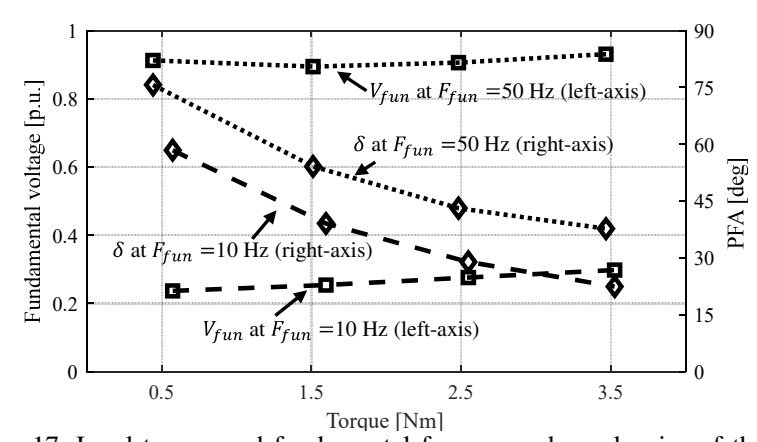

Fig. 17. Load torque and fundamental frequency dependencies of the fundamental voltage and PFA.

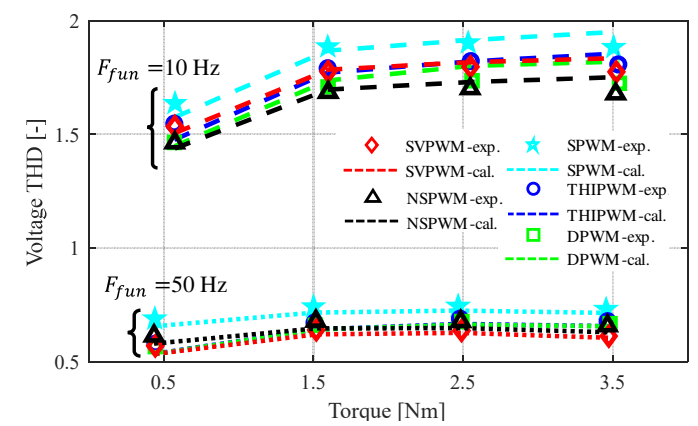

(a)

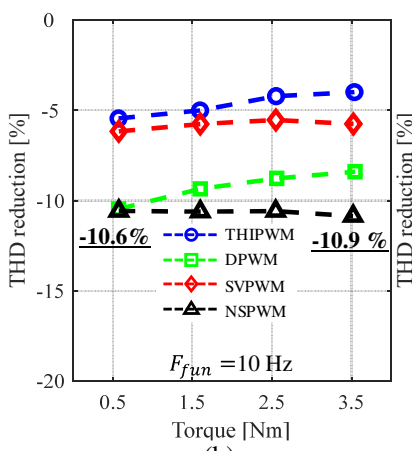

(b)

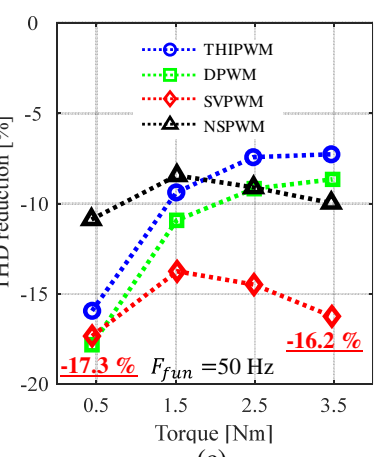

(c)
Fig. 18. Experimental results of (a) voltage THD, (b) and (c) THD reduction rate based on THD of SPWM with different operating condition.

voltage reference, thus the 4th and 6th-order components increase compared with SPWM (see Fig. 6). On the other hand, in (d) SVPWM and (e) NSPWM, odd-numbered multiple components exist, and it can be confirmed that the 7th-order component in SVPWM is larger than NSPWM. Note that the low-order harmonics (harmonic components below the carrier frequency) appear less than approximately $1 / 10$ of the high-order components and do not change depending on the modulation method, thus the low-order harmonics are not mentioned in this paper.

5.2 Characteristics of the Voltage THD Experiments are carried out when the load torque and the fundamental frequency are changed as shown in Fig. 17, which shows the characteristics of the fundamental voltage $V_{f u n}$ and PFA $\delta$. Here, the fundamental voltage $V_{f u n}$ (vertical axis on the left side) is normalized by the maximum phase voltage $\left(V_{d c 1} / 2\right)$ when SPWM is used. This result indicates that PFA decreases as the load torque increases, and the fundamental voltage increases as the frequency (rotor speed) increases.

In order to verify the effect of reducing voltage harmonics in each modulation methods described in Chapter 3 , the voltage THD characteristics are experimentally obtained under the conditions 
shown in Fig. 17. Fig. 18 (a) shows the experimental results of voltage THD characteristics, in which the dotted and dashed lines denote the theoretical calculation results in the case of $F_{\text {fun }}$ is 10 $\mathrm{Hz}$ and $50 \mathrm{~Hz}$, respectively. In addition, the reduction rate of the voltage THD based on the SPWM result are shown in Fig. 18 (a) and (b). Note that THD calculation are performed up to $30 \mathrm{kHz}$; since the carrier frequency is $5 \mathrm{kHz}$, up to 6 times of the carrier harmonic components are taken into account in this experiment. The voltage THD is small in the low torque and high speed region, and is large in the opposite condition; this result is similar to Fig. 12 (a), and it can be confirmed that the other methods also agrees with the theoretical calculation (see Fig. 18 (a)). The THD reduction rate when compared with SPWM is smaller than $0 \%$ under all conditions in four methods, thus the voltage THD can be reduced by increasing the modulation index. In particular, it is verified that the voltage THD is reduced by $10.9 \%$ by using NSPWM at low speed $\left(F_{\text {fun }}=10 \mathrm{~Hz}\right)$, and is reduced by $17.3 \%$ by using SVPWM at high speed $\left(F_{\text {fun }}=50 \mathrm{~Hz}\right)$. Furthermore, in the case of using DPWM at the torque of $0.5 \mathrm{Nm}$, which means the low PFA condition, the same reduction rate as NSPWM and SVPWM is obtained.

5.3 Inverter, Motor, and total Efficiency Characteristics Inverter efficiency and motor efficiency are measured to confirm the effect of decreasing the number of commutations and the effect of reducing the voltage THD due to changing modulation methods.

Fig. 19 shows the experimental results of inverter efficiency at the same condition as shown in Fig. 17. In DPWM, SVPWM, and NSPWM, the number of commutations in a switching period is $2 / 3$ of that in the case of SPWM and THIPWM, hence the inverter efficiency is increased. In particular, at the lowest load (torque of $0.5 \mathrm{Nm}$, fundamental frequency of $10 \mathrm{~Hz}$ ), an improvement in inverter efficiency of 2.9 percentage points (pp) is confirmed. Here, the difference in inverter efficiency between SVPWM, DPWM, and NSPWM is considered to be related to the output time of the zero vector. The output time of the zero vector is absolutely zero in NSPWM, and exists in SVPWM and DPWM, which matches the magnitude relationship of efficiency (see Fig. 10 (f)).

Figs. 20 and 21 show the experimental results of motor efficiency and total efficiency obtained under the same conditions as the inverter efficiency. Note that in the results of total efficiency, to clarify the difference in total efficiency depending on the modulation method, the vertical axis represents the difference based on the total efficiency in the case of using SPWM in \% (shown in Fig. 21); hence when the result is a positive value, the total efficiency is higher than SPWM, and when the result is negative, the total efficiency is lower than SPWM. The results of total efficiency when using SPWM are shown in the appendix. Here, the reason why the maximum motor efficiency is obtained at the fundamental frequency of $10 \mathrm{~Hz}$ and the torque of $1.5 \mathrm{Nm}$, and at $50 \mathrm{~Hz}$ and $2.5 \mathrm{Nm}$ is that: the maximum efficiency can be obtained when the motor PFA is approximately $45 \mathrm{deg}{ }^{(20)}$. The change in motor efficiency due to the modulation method is small compared that due to the load condition. However, the improvement effect is confirmed from the total efficiency (see Fig. 21). In the region where the torque is $1.5 \mathrm{Nm}$ or more, the total efficiency is improved in the case of SVPWM and NSPWM compared with other methods. At $10 \mathrm{~Hz}$ (shown in Fig. 21 (a)), the efficiencies of SVPWM and NSPWM are similar, which is the improvement effect of the output voltage THD (see Fig. 18 (b)). In addition, it is confirmed that SVPWM at $0.5 \mathrm{Nm}$ improved the total efficiency by $2.6 \%$

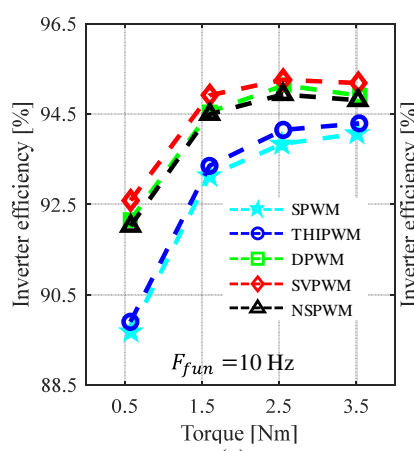

(a)

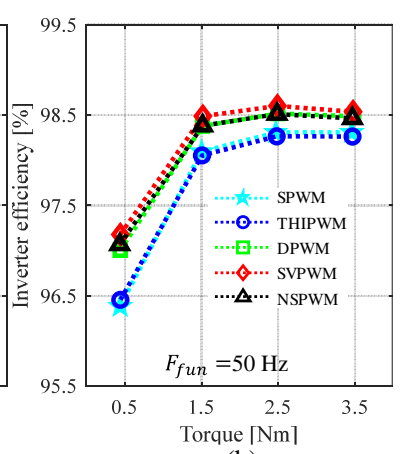

(b)
Fig. 19. Experimental results of the inverter efficiency with different operating condition when the fundamental frequency $F_{\text {fun }}$ is (a) $10 \mathrm{~Hz}$ and (b) $50 \mathrm{~Hz}$.

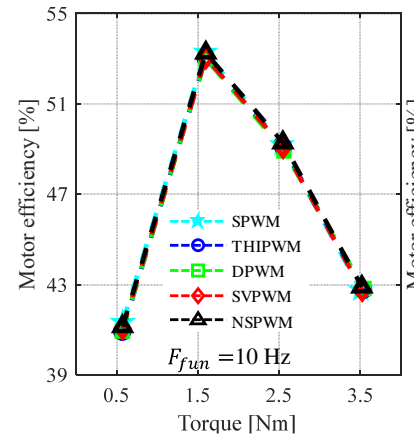

(a)

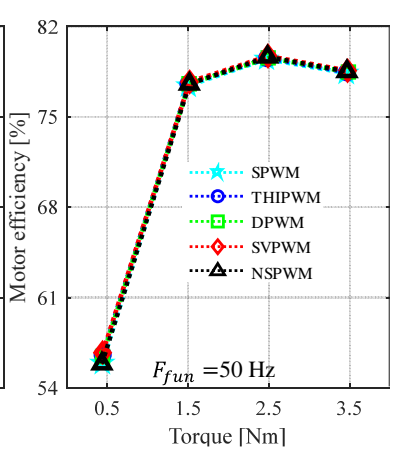

(b)
Fig. 20. Experimental results of the motor efficiency with different operating condition when the fundamental frequency $F_{\text {fun }}$ is (a) $10 \mathrm{~Hz}$ and (b) $50 \mathrm{~Hz}$.

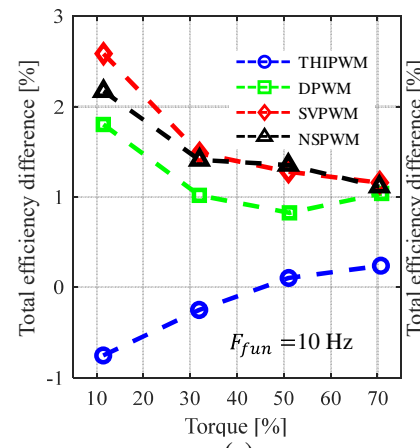

(a)

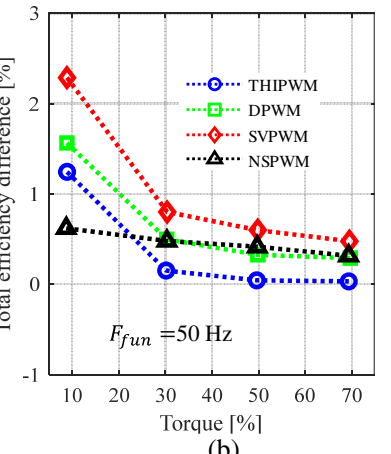

(b)
Fig. 21. Efficiency difference of the total efficiency (in \%) based on the total efficiency of SPWM with different operating condition when the fundamental frequency $F_{\text {fun }}$ is (a) $10 \mathrm{~Hz}$ and (b) $50 \mathrm{~Hz}$.

compared with SPWM. The reason why the total efficiency in THIPWM is worse than in SPWM is considered as, the number of commutations is the same as SPWM, and the floating capacitor voltage is large (described in 5.1).

\section{Conclusions}

In this paper, the output voltage harmonics when operating the dual inverter, based on a method for reducing the voltage harmonics, in the case of using typical modulation methods (SPWM, THIPWM, DPWM, SVPWM, and NSPWM) are theoretically analyzed. Analysis is performed focusing on the change in the output time of the voltage vector in each modulation method due to the fundamental voltage and the load power factor angle in the dual inverter with floating capacitor topology. In addition, the improvement of voltage THD and efficiency is verified by using a dual inverter fed OEWIM in the experiment. By using the method 
for maximizing modulation index of both inverters in each modulation method, the following are confirmed from the experimental results: voltage THD reduction of $10.9 \%$ with NSPWM and $17.3 \%$ with SVPWM are obtained compared with SPWM; by reducing the number of commutations to $2 / 3$, the inverter efficiency in DPWM, SVPWM, and NSPWM is improved by up to $2.9 \mathrm{pp}$; and the total efficiency is improved by up to $2.6 \%$ in the low load region by using SVPWM.

By using the modulation methods based on the analysis results shown in this paper, it is possible to contribute to energy-saving at partial-load condition.

\section{References}

(1) Yohei Kubota, Keiichi Ishida, Masaki Kanamori, Yuki Yanase, Takahisa Endo, Yasushi Yamanashi, Hidetoshi Kanazawa, "Current Distortion Analysis of Three-Phase PWM Rectifier in Over-Modulation Region and Application to Air-Cooled Heat Pump Chiller," in IEEJ Journal of Industry Applications, Vol. 10, No. 3, pp. 384-392, 2021

(2) E. B. Agamloh, "The Partial-Load Efficiency of Induction Motors," IEEE Transactions on Industry Applications, vol. 45, no. 1, pp. 332-340, Jan.-feb. 2009.

(3) J. Ewanchuk, J. Salmon and C. Chapelsky, "A Method for Supply Voltage Boosting in an Open-Ended Induction Machine Using a Dual-inverter System With a Floating Capacitor Bridge," IEEE Transactions on Power Electronics, Vol. 28, No. 3, pp. 1348-1357, March 2013.

(4) C. Perera, G. J. Kish and J. Salmon, "Decoupled Floating Capacitor Voltage Control of a Dual Inverter Drive for an Open-Ended Winding Induction Motor," in IEEE Transactions on Power Electronics, vol. 35, no. 7, pp. 73057316, July 2020.

(5) Y. Oto, T. Noguchi, T. Sasaya, T. Yamada and R. Kazaoka, "Space Vector Modulation of Dual-Inverter System Focusing on Improvement of Multilevel Voltage Waveforms," IEEE Transactions on Industrial Electronics, Vol. 66, No. 12, pp. 9139-9148, Dec. 2019.

(6) Z. Huang, T. Yang, P. Giangrande, S. Chowdhury, M. Galea and P. Wheeler, "An Active Modulation Scheme to Boost Voltage Utilization of the Dual Converter With a Floating Bridge," in IEEE Transactions on Industrial Electronics, vol. 66, no. 7, pp. 5623-5633, July 2019.

(7) Yoshiaki Oto, Toshihiko Noguchi, "Fault-Tolerant Function of DC-Bus Power Source in A Dual-inverter Drive System and Its Operation Characteristics," IEEJ Journal of Industry Applications, Volume 8, Issue 6, Pages 953-959, 2019.

(8) W. Zhao, P. Zhao, D. Xu, Z. Chen and J. Zhu, "Hybrid Modulation FaultTolerant Control of Open-End Windings Linear Vernier Permanent-Magnet Motor With Floating Capacitor Inverter," IEEE Transactions on Power Electronics, Vol. 34, No. 3, pp. 2563-2572, March 2019.

(9) M. Nishio and H. Haga, "Single-Phase to Three-Phase Electrolytic CapacitorLess Dual Inverter-Fed IPMSM for Suppress Torque Pulsation," in IEEE Transactions on Industrial Electronics, vol. 68, no. 8, pp. 6537-6546, Aug. 2021.

(10) Ren Okumura, Hitoshi Haga: "Reduction of Input Current Harmonics Using Dual Inverter for Motor Drive", IEEJ Journal of Industry Applications, Volume 10, Issue 3, pp. 348-356 (2021).

(11) A. Amerise, M. Mengoni, L. Zarri, A. Tani, S. Rubino and R. Bojoi, "OpenEnd Windings Induction Motor Drive With Floating Capacitor Bridge at Variable DC-Link Voltage," in IEEE Transactions on Industry Applications, vol. 55, no. 3, pp. 2741-2749, May-June 2019.

(12) A. M. Hava and E. Ün, "Performance Analysis of Reduced Common-Mode Voltage PWM Methods and Comparison With Standard PWM Methods for Three-Phase Voltage-Source Inverters," in IEEE Transactions on Power Electronics, vol. 24, no. 1, pp. 241-252, Jan. 2009.

(13) A. M. Hava, R. J. Kerkman and T. A. Lipo, "Simple analytical and graphical methods for carrier-based PWM-VSI drives," in IEEE Transactions on Power Electronics, vol. 14, no. 1, pp. 49-61, Jan. 1999

(14) A. D. Kiadehi, K. E. K. Drissi and C. Pasquier, "Voltage THD Reduction for Dual-Inverter Fed Open-End Load With Isolated DC Sources," in IEEE Transactions on Industrial Electronics, vol. 64, no. 3, pp. 2102-2111, March 2017.

(15) A. Mizukoshi and H. Haga, "Improvement of Output Voltage Waveform in Dual-inverter Fed Open-winding Induction Motor at Low Speed Area," 2018 IEEE Energy Conversion Congress and Exposition (ECCE), Portland, OR,

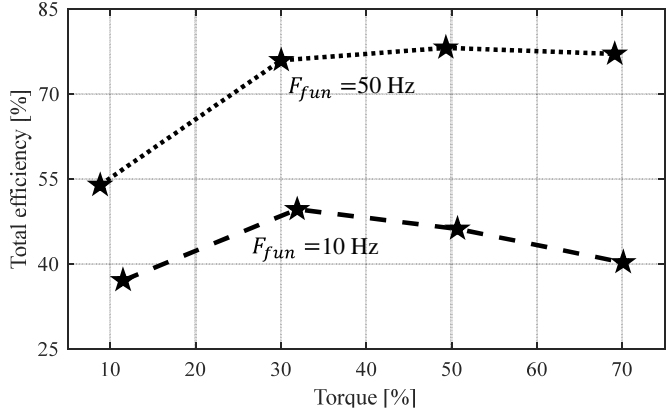

app. Fig. 1. Experimental results of the total efficiency when using SPWM with different operating condition.

2018, pp. 5422-5427.

(16) Akihito Mizukoshi, Hitoshi Haga, "Control Method for Reducing the Motor Loss of Dual-inverter Fed Open-end winding Induction Motor in the Lowspeed Region," IEEJ Journal of Industry Applications, 2020, Volume 9, Issue 1, Pages 27-35.

(17) A. Mizukoshi and H. Haga, "Reduction of Voltage Harmonics in an OpenEnd Winding Induction Motor Driven by a Dual-Inverter with FloatingCapacitor in the Low-Speed Region," 2020 IEEE Energy Conversion Congress and Exposition (ECCE), Detroit, MI, USA, 2020, pp. 2656-2661.

(18) E. Un and A. M. Hava, "A Near-State PWM Method With Reduced Switching Losses and Reduced Common-Mode Voltage for Three-Phase Voltage Source Inverters," in IEEE Transactions on Industry Applications, vol. 45, no. 2, pp. 782-793, March-april 2009.

(19) K. Yamazaki and N. Fukushima, "Iron Loss Model for Rotating Machines Using Direct Eddy Current Analysis in Electrical Steel Sheets," IEEE Transactions on Energy Conversion, vol. 25, no. 3, pp. 633-641, Sept. 2010.

(20) I. J. Smith and J. Salmon, "High-Efficiency Operation of an Open-Ended Winding Induction Motor Using Constant Power Factor Control," IEEE Transactions on Power Electronics, Vol. 33, No. 12, pp. 10663-10672, Dec. 2018.

(21) K. A. Corzine, S. D. Sudhoff and C. A. Whitcomb, "Performance characteristics of a cascaded two-level converter," IEEE Transactions on Energy Conversion, Vol. 14, No. 3, pp. 433-439, Sept. 1999.

\section{Appendix}

The result of the total efficiency of SPWM used for the calculation of the total efficiency difference (shown in Fig. 21) is shown in app. Fig. 1.

Akihito Mizukoshi (Student member) received the B.E. degrees in

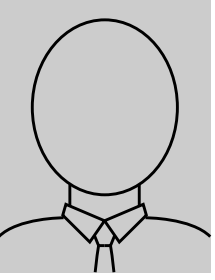

Hitoshi Haga

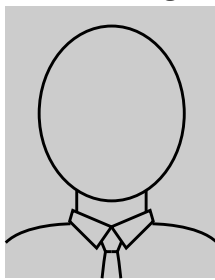
electrical, electronics and information engineering from Nagaoka University of Technology, Niigata, Japan in 2017. Presently, he has been in 5-year integrated doctoral course of Nagaoka University of Technology. He is a student member of IEEJ and IEEE. His main research interests include motor drives and inverters. Associate Professor in 2016. His research interests include power electronics. 